\title{
Cash transfers in South Africa: their role in short-run poverty alleviation and human capital investment
}

\author{
Ingrid Woolard, University of Cape Town
}




\section{Objectives of cash transfer programmes}

- Short-run effect on poverty through putting cash into poor households.

- Long-run poverty alleviation through investment in human capital (nutrition, health, education). 


\section{Social security in South Africa}

Social insurance - Unemployment Insurance - is paid to about 207000 individuals each month (about $5 \%$ of the unemployed). It is a contributory scheme and accounts for $0.2 \%$ of GDP

Social assistance - unconditional cash transfers - go to 14 million individuals (about $30 \%$ of the population) each month and accounts for $3.5 \%$ of GDP

Targeted at vulnerable groups: the major grant types are the State Old Age Pension, the Disability Grant, the Child Support Grant and the Foster Care Grant. 


\section{Spending on education, health and cash transfers}

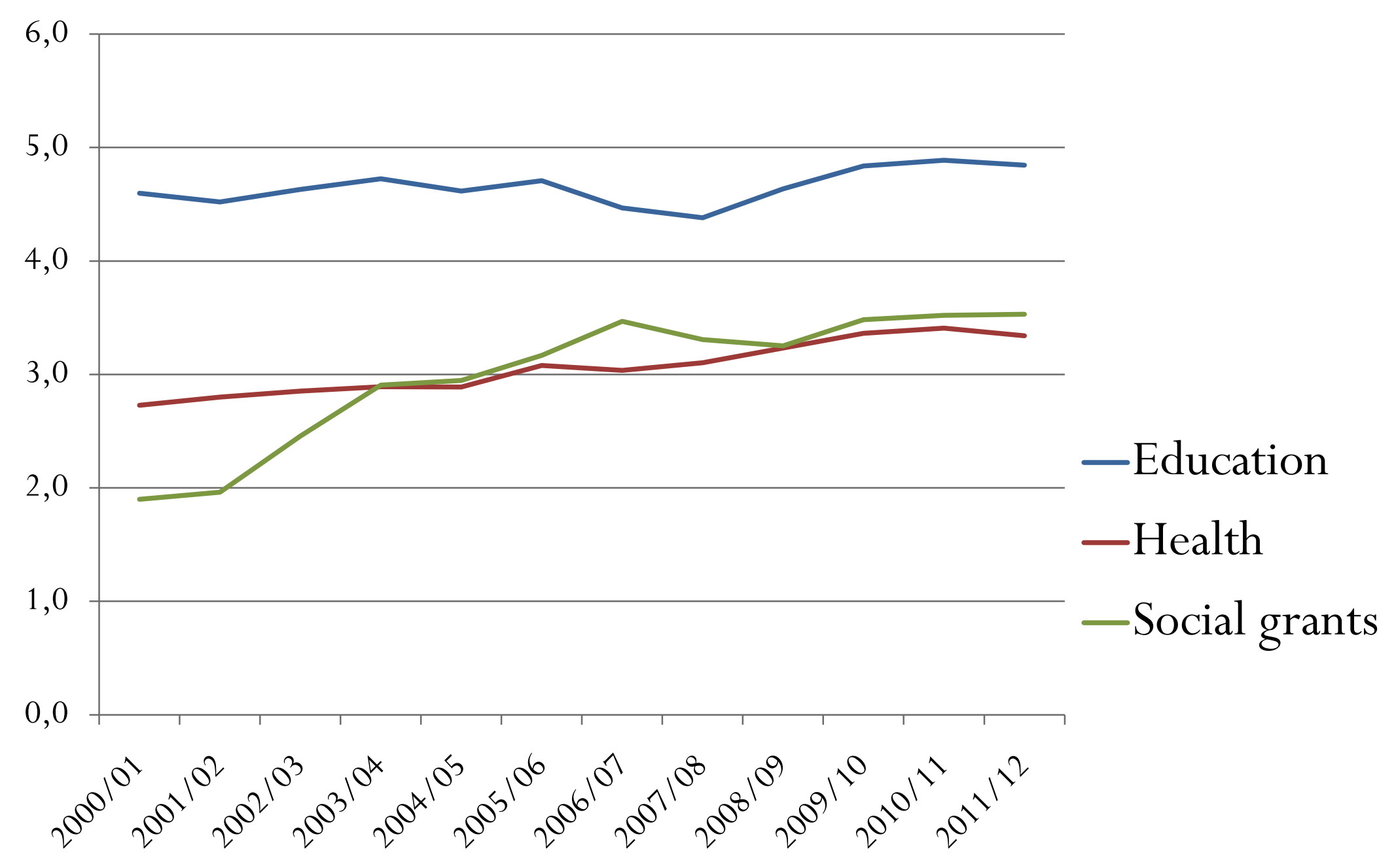




\section{The size of the payments}

- The Old Age Pension and Disability Grant are about PPP $\$ 240$ per month

- The Child Support Grant is about PPP\$55 per month

- Grants are means-tested - about $80 \%$ of the elderly and two-thirds of children are income eligible 


\section{Are the grants pro-poor?}

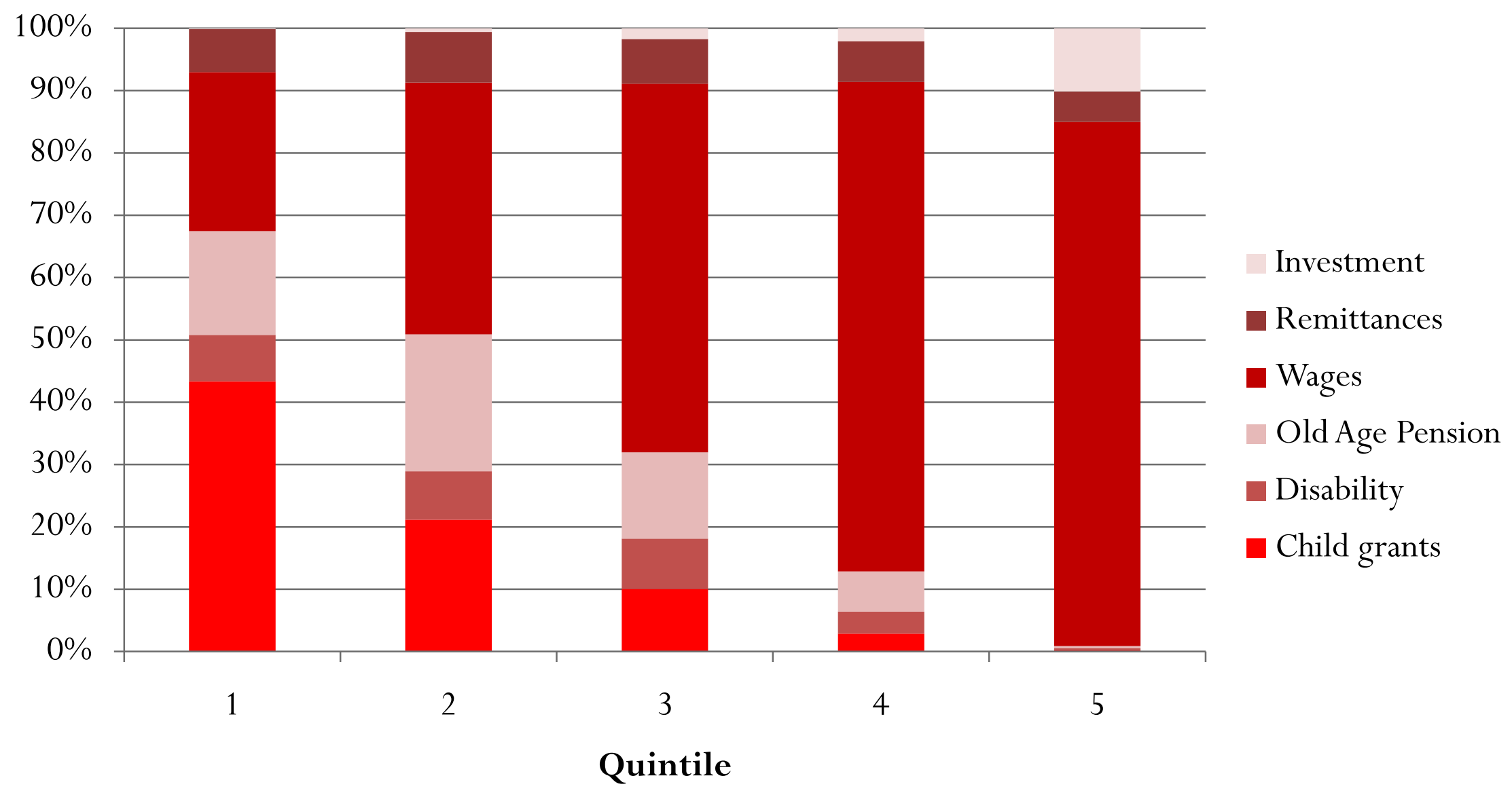

Source: National Income Dynamics Study, 2008 


\section{$\%$ households reporting any grant income}

\begin{tabular}{|c|c|c|c|c|c|c|}
\hline Quintile & 1997 & 2002 & 2003 & 2004 & 2005 & 2006 \\
\hline 1 & 15.9 & 32.0 & 31.7 & 40.2 & 47.7 & 69.4 \\
\hline 2 & 54.0 & 55.8 & 50.9 & 71.2 & 73.3 & 69.9 \\
\hline 3 & 46.7 & 51.6 & 53.2 & 67.1 & 69.1 & 69.4 \\
\hline 4 & 33.8 & 33.2 & 34.8 & 35.8 & 40.1 & 45.4 \\
\hline 5 & 14.0 & 11.3 & 7.9 & 8.8 & 10.0 & 12.0 \\
\hline Total & 32.9 & 36.8 & 32.0 & 38.6 & 45.5 & 55.2 \\
\hline
\end{tabular}

Source: Own calculations using OHS (1997) and GHS (2002, 2003, 2004, 2005, 2006) 


\section{Poverty with and without grants}

Poverty measures when cash transfers are included

\begin{tabular}{|c|c|c|c|c|c|c|}
\hline Year & \multicolumn{3}{|c|}{ Poverty line PPP\$7 } & \multicolumn{4}{|c|}{ Poverty line PPP\$3.80 } \\
\hline & P0 & P1 & P2 & P0 & P1 & P2 \\
\hline 1993 & 0.72 & 0.66 & 0.49 & 0.56 & 0.57 & 0.40 \\
\hline 2000 & 0.71 & 0.63 & 0.46 & 0.54 & 0.54 & 0.36 \\
\hline 2008 & 0.70 & 0.63 & 0.46 & 0.54 & 0.52 & 0.34 \\
\hline
\end{tabular}

Poverty measures when cash transfers are excluded

\begin{tabular}{c|c|c|c|c|c|c} 
Year & \multicolumn{3}{|c|}{ Poverty line PPP\$7 } & \multicolumn{4}{c}{ Poverty line PPP\$3.80 } \\
\hline 1993 & 0.73 & 0.72 & 0.59 & 0.60 & 0.68 & 0.54 \\
\hline 2000 & 0.72 & 0.69 & 0.55 & 0.57 & 0.64 & 0.50 \\
\hline 2008 & 0.71 & 0.76 & 0.65 & Q.60 & 0.72 & P1 0.61
\end{tabular}

- Grant income does not change the headcount (p0) substantially.

- For p1 and p2 (depth of poverty) there is a marked improvement due to grants.

- This effect was especially strong between 2000 and 2008, coinciding with the roll-out of the Child Support Grant. 


\section{The Impact of Grants on Education}

- Samson et al. (2001) find that pension receipt positively impacts on school attendance, particularly for girls.

- Hamoudi \& Thomas (2005) find that children living with a pensioner have an average of a quarter year more schooling 5 years later on than those without.

- Case \& Ardington (2006) find that the presence of a pensioner mitigates the negative effect of orphanhood on a child's enrolment and progression, but only if the pensioner is female.

- Boler \& Timaeus (2006) find that receipt of the CSG mitigates the negative effect of orphanhood on older children ages 13-16.

- Case et al. (2005) find that receipt of the CSG increases 6 year old school enrolment by $8.1 \%$ and for 7 year olds by $1.8 \%$ 


\section{The Impact of Grants on Health}

- Case (2001) finds that pension receipt improves the health not only of the pensioner, but of those living in the same household.

- Duflo (2000) finds that the presence of a female pensioner has positive health improvements for young girls but the presence of a male pensioner has no health benefits for young children.

- Aguero et al. (2008) find that receipt of the CSG in the first 36 months of life significantly improves the height-for-age ratio. 


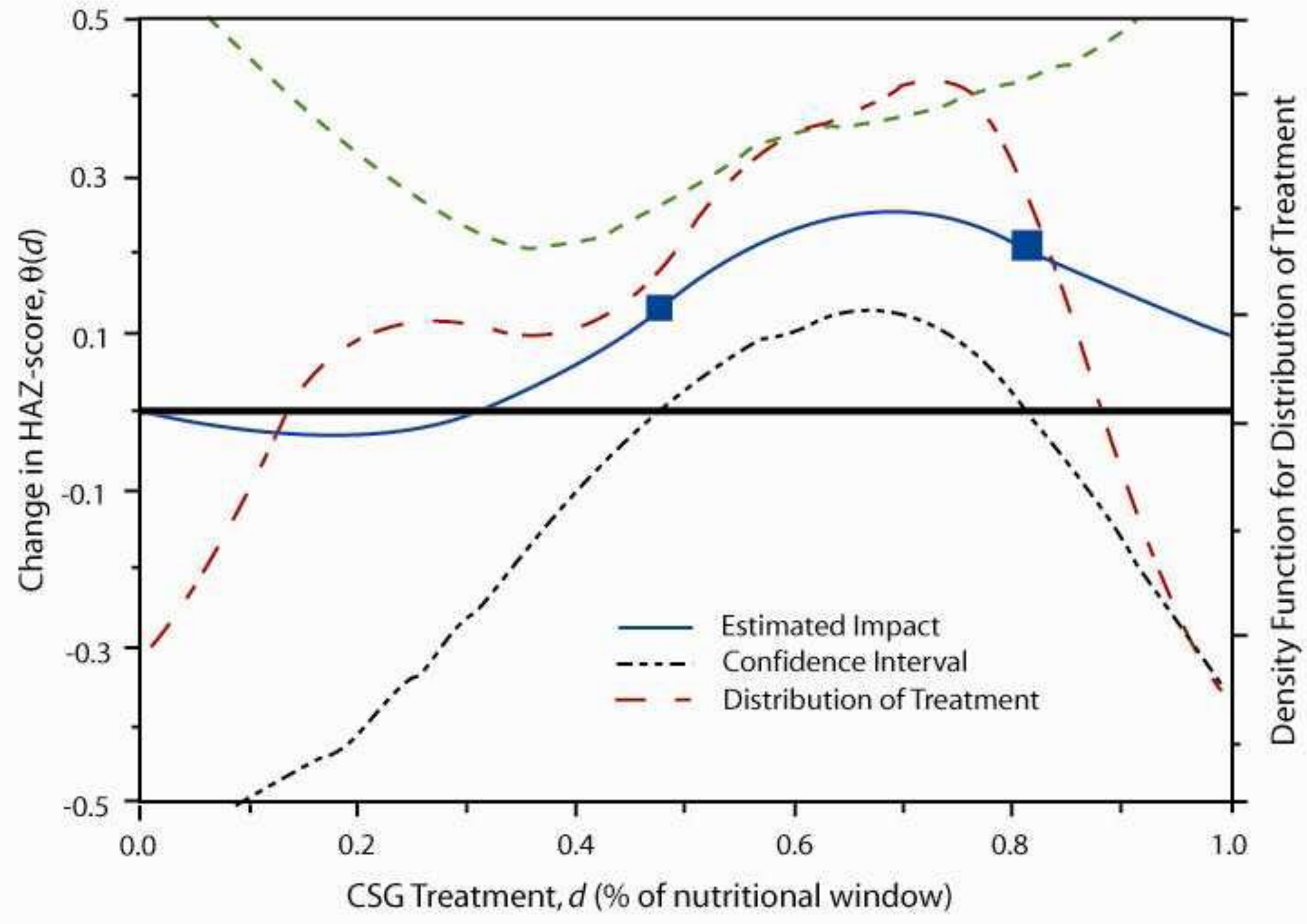

Source: IPCWorking Paper Number 39 


\section{The Impact of Grants on Labour Participation}

- Bertrand et al. (2000) find a reduction in working hours of members of working age when another household member reaches pensionable age. The reduction is greater for female pensioners, women tend to reduce their working hours less than men and eldest sons tends to reduce their working hours more than others.

- Posel et al. (2004) hypothesise that pension receipt provides the means to migrate, and/or the means for the pensioner to care for the children of the migrant. This result differs to Bertrand et al. due to the inclusion of non-resident household members. 


\section{Conclusion}

- The extensive system of cash transfers in South Africa is

- Pro-poor

- Cost effective (although not discussed here)

- Incentive compatible

- Financially sustainable

- There is some evidence of longer-run impacts on investments in human capital, but cash transfers are not a silver bullet... need a comprehensive and coherent anti-poverty strategy that tackles poverty from all sides 


\section{Thank you for your time}

I gratefully achknowledge support from the UK Economic and Social Research Council (RES-167-25-0076) 